\title{
PROPOSTA DE IMPLEMENTAÇÃO ESTRATÉGICA DO CAPITAL INTELECTUAL COMO UM DIFERENCIAL COMPETITIVO: ESTUDO DE CASO REALIZADO NA EMPRESA FC PARAFUSOS
}

\section{ARTIGO ORIGINAL}

INÁCIO, Alexandre Gonçalves ${ }^{1}$

SILVA, Francisco David Santos da ${ }^{2}$

ATAIDE, Julioney Ferreira ${ }^{3}$

ROBERTO, José Carlos Alves ${ }^{4}$

INÁCIO, Alexandre Gonçalves. Et al. Proposta de Implementação Estratégica do Capital Intelectual como um diferencial competitivo: Estudo de caso realizado na Empresa FC parafusos. Revista Científica Multidisciplinar Núcleo do Conhecimento. Ano 05, Ed. 11, Vol. 11, pp. 21-41. Novembro de 2020. ISSN: 24480959,

acesso:https://www.nucleodoconhecimento.com.br/administracao/estrategica-do-

capital

\section{RESUMO}

O presente artigo teve como objeto de estudo a empresa FC Parafusos. Seu objetivo geral consistiu em analisar uma melhor gestão de desempenho e identificar o capital intelectual em todas os setores da organização. Auxiliado pelos objetivos específicos

\footnotetext{
${ }^{1}$ Graduação em Administração.

2 Graduação em Administração.

${ }^{3}$ Graduação em Administração.

${ }^{4}$ Orientador. Mestrado profissional em Engenharia de produção. Especialização em Gestão em Logística empresarial. Graduação em Administração com Ênfase em Marketing.
} 
buscou-se conhecer os processos, avaliar que o capital humano é um excelente diferencial para o sucesso da empresa e propor ações para indicar o desempenho organizacional junto ao capital intelectual. O projeto surgiu a partir de estudos da análise das áreas funcionais, onde identificamos a área de recursos humanos como a mais crítica. Realizou-se uma pesquisa qualitativa, empregando como instrumento de coleta de dados as entrevistas, visitas com observação direta e análise documental. A ferramenta interventiva utilizada foi $\circ 5 \mathrm{~W} 2 \mathrm{H}$, para a melhoria das ações de implementação estratégica do capital intelectual como diferencial competitivo e sugestionar indicadores de desempenho do processo e do produto para o crescimento da FC Parafusos.

Palavra-chave: organizações, intelectual, implementação estratégica.

\section{INTRODUÇÃO}

Independentemente de reconhecerem o mérito dos meios de mensuração, a maioria dos sistemas administrativos, poucas a empresas que criam processos que tem a competência de uma forma única e integrada de relatar o propósito de suas estratégias, que, inclusive é mais importante do que apenas elaborar e redigir estratégias, a disposição de monitorar e fazer correções tornou-se uma norma crítica, que atualmente, em virtude das circunstâncias de um modo geral mais turbulento, carregado de dúvidas e com níveis de disputa.

Neste conceito, modelos de análise de capital intelectual que não sejam projetados para esclarecer, promover e conduzir a materialização das aspirações apontadas no decorrer das definições de estratégias tendem a ser rapidamente ignorados. Nosso estudo aqui desenvolvido investiga uma excelente estratégia do capital intelectual com enfoques na gestão de desempenho, competitividade e gestão de valor.

Diversos mecanismos foram inseridos para a medição de desempenho nos mais diversos cenários e níveis organizacionais, apesar de que os indicadores lastreados são apenas por referências financeiras fossem pouco para caracterizar o 
desempenho, não faziam presentes - reunidos num único conceito - capitais com a aptidão de indicar simultaneamente o patamar de competição de uma coordenação.

Desse modo, defende-se a tese da importância da avaliação do capital intelectivo em organizações com um diferencial competitivo e também da viabilidade da elaboração de um modelo de avaliação de capital intelectual capaz de evidenciar os ativos intangíveis críticos da FC Parafusos fazendo uma análise profissional na empresa para obter as finalidades.

A partir do modelo de gestão do capital intelectual, os novos modelos se manifestam como organização de experiência gestão do conhecimento e do capital intelectual, gestão do aperfeiçoamento e visões de coordenação contemporânea. Assim, apresenta-se uma visão sobre a desenvolvimento dos modelos de gestão, bem como da concepção da qualidade total, uma seleção de conceitos de diferentes propostas para atuação em gestão e, então, uma integração desses conceitos, direcionados a confrontar as transformações e modificações.

\section{REVISÃO BIBLIOGRÁFICA}

A fundamentação teórica consiste na revisão de texto, artigos, livros ou todo material pertinente a revisão bibliográfica. Conhecida também como revisão de literatura, tratase de abordar os principais pontos de um tema, visto pelos principais autores. Para Liborio (2015, p.40) "refere-se a parte do desenvolvimento propriamente dito, em que o autor expõe as afirmações de outros teóricos e pesquisas relacionadas ao tema, discutindo-as conforme a perspectivas do seu próprio trabalho".

Diante disso, a revisão bibliográfica é a base que sustenta qualquer pesquisa, é através dela que podemos referir e validar o conhecimento produzido, destacando conceitos e procedimentos relevantes para a pesquisa, além de possibilitar o entendimento do mesmo diante do que foi estudado e analisado por teóricos.

\subsection{CONCEITO DE CAPITAL INTELECTUAL}


É um conjunto de benefícios intangíveis que agregam valor às empresas. Moreira; Violin e Silva (2014), consideram "o capital intelectual como sendo a soma do conhecimento de todas as pessoas em uma empresa, que proporciona vantagem competitiva".

É possível afirmar que o capital intelectual que uma organização possui é o seu recurso de maior valor. E em contrapartida, este é um retorno de grande importância para a mesma, que não são encontrados quando não se investe no conhecimento, no fator humano (MOREIRA, 2014, p.6).

No entanto, o capital intelectual é denominado como o novo proveito competidor, ou seja, ele é o diferencial na obtenção de sucesso das organizações. É através dele que a corporação consegue se desenvolver e se destacar no mercado em que atua.

Ele é dividido em três classes, que são conhecidas da seguinte maneira:

- Humano: são os recursos humanos da organização. Nele envolve-se o conhecimento, experiência, poder de inovação, habilidades e competências dos empregados.

- Estrutural: nele envolve-se o uso das ferramentas e informações da organização. Além de envolver os sistemas de informações, o software, os bancos de dados e todo o resto da capacidade organizacional que apoia a produtividade do capital humano.

- Relacional: representa os relacionamentos internos e externos, como a marca e credibilidade. A qualidade da base dos clientes depende muito de colaboradores com esse potencial de atrai-los e retê-los.

\subsection{GESTÃO DE PESSOAS NAS ORGANIZAÇÕES}

O departamento de gestão de pessoas surgiu através da preocupação das organizações em valorizar o capital humano para garantir o sucesso da empresa. DUTRA (2009, apud RIBEIRO et al., 2014, p.56) "considera a gestão de pessoas como um conjunto de políticas e práticas que permitem a conciliação das expectativas entre a organização e as pessoas para que ambas possam realizar-se ao longo do tempo". 
O modelo de gestão de pessoas transcende a operação dos tradicionais subsistemas (seleção, treinamento, remuneração etc.) e abrange princípios, conceitos, políticas, práticas e prioridades em uma organização, que fundamentam a definição e a utilização de ferramentas de gestão para direcionar o comportamento humano no trabalho, incluindo estratégias de ação de gestores e funcionários, líderes e liderados (DERNER, 2013, p.17-18).

No entanto a gestão de pessoas consiste no gerenciamento e administração do capital humano, ao qual tem sido bastante valorizado pelas organizações, pois elas entenderam que se as pessoas tiverem oportunidade de progressão, elas vão dar o melhor delas, originando resultados positivos para a empresa.

\subsection{ATRAINDO E RETENDO O CAPITAL INTELECTUAL}

O desafio das organizações é atrair e reter criadores de conhecimento. As organizações atualmente compreendem que seu fundamental ativo não é o financeiro e sim o humano, que é um capital complexo para ser contabilizado, entretanto que dá ao empreendimento um amplo diferencial, ou seja, é considerado como seu fator de concorrência. Chiavenato (2006 apud RIBEIRO, 2014, p.4) afirma que a gestão de pessoas está dividida em seis processos: agregar pessoas, aplicar pessoas, recompensar pessoas, desenvolver pessoas, manter pessoas e monitorar pessoas.

Gerir pessoas envolve muito mais que um gerente ou executivo, envolve toda a cúpula que busca construir uma equipe de trabalho com cabeças compromissadas com os objetivos da empresa. Diante da nova configuração, com transformações e mudanças repentinas as organizações estão se adequando às técnicas novas de valorização humana e profissional (MENEZES, 2013, p.8).

Deste modo, contar com uma boa gestão de capital intelectual facilita a retenção dos talentos da empresa, evitando que eles se sintam propensos a aceitar novos desafios em outras empresas. Pois se os funcionários percebem sua valorização e seu desempenho mediante a atividade ao qual foi solicitado, maiores são as chances de ele trabalhar mais engajado e alinhados com os objetivos da empresa.

\subsubsection{A VALORIZAÇÃo DAS PESSOAS NO AMBIENTE DE TRABALHO}


As pessoas são fontes de concorrência, já que possuem valores e não são imitadas com facilidade. Muitos empreendimentos não apreciam o conhecimento de seus contribuintes, pois ainda estão ligadas a Era Industrial, tendo como resultado pouca permanência no mercado. Cassol et al. (2014) a empresa é desafiada a ver o colaborador não somente como um funcionário, mais como pessoas capacitadas de habilidades únicas que possuem o capital intelectual da organização para gerar melhores resultados.

A transformação organizacional só se efetiva com as pessoas, para as pessoas e através do envolvimento e do comprometimento das pessoas. Portanto, a cultura da organização deve se fundamentar na valorização do ser humano, de seu trabalho, da inteligência que ele aplica nesse trabalho e na geração de conhecimento organizacional advinda da interrelação pessoas/saber/organização. (FISCHER, 2002, p. 154 apud MARRAS, 2012, p.07).

Encontrar-se nas pessoas a competência de renovar e inovar procedimentos, são considerados as soluções incomuns e intangíveis de uma organização, daí a principal importância delas. As pessoas são possuidoras do capital intelectual, as empresas têm como função análise o intelectivo humano em riquezas. Para se sustentar nesse mercado cruel, as organizações enfrentam intensas tarefas, mas para isso precisam da assistência das pessoas.

\subsection{COMO RELACIONAR INDICADORES DE DESEMPENHO ORGANIZACIONAL AO CAPITAL INTELECTUAL}

O processo de desempenho organizacional e capital Intelectual objetiva gerenciar o quê e como as ações são desenvolvidas, com o propósito de cumprir as metas sobrepostas pela organização, através do desenvolvimento da capacidade geracional de receitas e valores, para clientes e acionistas.

No passado, essas metas continham apenas indicadores financeiros para medir o desempenho. Com o advento do balanced scorecard (BSC) de Kaplan e Norton (1997), muitas empresas incorporaram os indicadores do BSC que além dos elementos financeiros, incluem fatores relacionados aos clientes, aos processos internos e às perspectivas de aprendizado e crescimento (MARRAS, 2012, p.53-54). 
Em outas palavras, consiste em uma análise das ações realizadas dentro da organização e, ainda a verificação do desempenho das mesmas, de modo a estarem caminhando na direção dos objetivos e metas traçados. Edvinson (2013) confere ao capital intelectual um estudo interdisciplinar sistemático, denominado ciência de sistemas de capital intelectual que retrata a respeito dos recursos intelectuais, nos quais podem ser identificados, consolidados, compartilhados e usados para um bem maior, a níveis individuais, organizacionais e sociais.

Tal acompanhamento permite aos gestores tomar decisões que almejem o melhoramento dos processos empresariais e, consequentemente, a maximização dos resultados diante de um determinado composto de recursos disponíveis.

Deste modo, as medições são importantes a compreensão do que se está acontecendo no ambiente; a realização de uma análise sobre a necessidade de alguma mudança, bem como a análise sobre o impacto da mudança implementada; a garantia da preservação dos ganhos obtidos; a correção das condições fora de controle e, ainda a fixação de prioridades. Portanto, a sua inexistência prejudicaria de modo significativo as possíveis melhorias na organização, visto que sem as medições necessárias não haverá o conhecimento.

O propósito das medições, em primazia, é fornecer informações qualitativas e quantitativas melhorando, assim, o nível de conhecimento interno da organização. Desta forma, para que o sistema de medições seja totalmente eficiente, o mesmo deve estabelecer prioridades a todos os envolvidos, visto que sem o uso dos indicadores e das medições de desempenho, o processo de tomada de decisão da companhia será prejudicado.

Para isso, o desempenho organizacional deve promover uma ligação sistemática entre as estratégias de organização, os recursos e os processos, de maneira estruturada, a fim de promover constantemente melhorias a organização, de modo que todos compreendam onde se está e aonde se pretende chegar. 
Em síntese, o processo de gestão possibilita aos responsáveis pela tomada de decisão, o gerenciamento das ações desenvolvidas no setor empresarial, de modo a acompanhar o desenvolvimento destas, observando se elas estão direcionadas aos resultados desejados.

\subsection{DIFERENCIAL COMPETITIVO}

O diferencial competitivo é o que permite a empresa destacar-se entre as concorrentes e enfatizarem suas ofertas perante seu público-alvo. Para Derner (2013, p. 22) "é a habilidade de produzir produto ou serviço tido como valioso, de modo que ninguém consiga imita-lo, diferenciando deste modo a organização perante suas concorrentes". Ou seja, o produto, serviço ou qualidade do serviço precisa despertar o desejo do consumidor e apresentar uma solução para algum problema dele.

Sob a perspectiva econômica, em um cenário competitivo, a busca por vantagens representa o movimento estratégico adotados pelas empresas. Neste sentido, o autor ressalta que a "competitividade" deveria ser buscado pelos agentes, a fim de obter um melhor posicionamento estratégico no mercado (LEITE, 2008 apud DERNER, 2013).

Algumas características do diferencial competitivo é não ser imitado facilmente, ser único, ser sustentável e ser superior aos outros concorrentes. Por isso a vantagem competitiva ou diferencial competitivo possui um diferencial de difícil imitação pelos seus concorrentes.

Portanto competir através de diferenciais significa duas coisas, foco no seu alvo e foco na divulgação desse diferencial, mas para isso a empresa deve ter por exemplo, qualidade no seu atendimento, destacando-se das outras.

\subsubsection{COMO USAR CAPITAL INTELECTUAL COMO DIFERENCIAL COMPETITIVO}

Empresas que não conseguem reter, atrair, desenvolver e aproveitar seu capital humano, correm o risco de dar ao rival uma mina de ouro, uma vez que a sua aquisição em um colaborador pode ser perdida, mas isso não significa que a empresa não deva 
investir, o oposto o investimento nas pessoas é de essencial importância, porém para que seus investimentos não se percam é imprescindível instruir-se.

Nunes (2013) relata que no auge da evolução do foco estratégico, a competição pelos talentos e os sonhos fazia-se presente, nos quais o capital intelectual das pessoas, já era tido como o recurso estratégico mais relevante. Neste contexto, o desenvolvimento do capital humano potenciando assim o capital intelectual é a chave para a construção da vantagem competitiva das organizações nos dias de hoje.

Deste modo, de acordo com a citação acima dá para concluir que a vantagem competitiva pode ser adquirida e mantida através da gestão do capital intelectual.

\section{MATERIAIS E METODOS}

A metodologia trata-se de detalhar os instrumentos e procedimentos metodológicos utilizados pelo pesquisador para realização da pesquisa. Segundo Japiassú (2013) dispõe que este item do trabalho é o que será lido com mais frequência, portanto o pesquisador deve utilizá-lo para evidenciar as conquistas alcançadas no decorrer do trabalho e fazer menção ao proposto nos objetivos gerais.

No entanto a metodologia deste artigo tem uma abordagem quantitativa porque foram realizadas pesquisas bibliográficas, documental e de campo focadas em apresentar nossas propostas e quais os métodos que iremos utilizar para identificar como a gestão de indicadores de desempenho organizacionais podem influenciar na definição de um plano estruturado de desenvolvimento do capital intelectual com o intuito de melhorar os processos organizacionais da empresa em questão.

\subsection{PROCEDIMENTOS METOLÓGICOS}

A ideia dos nossos procedimentos metodológicos é descrever como vamos apresentar nossas propostas, concepções e quais ideias iremos utilizar neste projeto para definir nossas propostas, assim alcançando o objetivo de nossa pesquisa. De acordo com as afirmações de Ricier e Fregoneze (2014) o pesquisador precisa escolher o método 
e o tipo de pesquisa adequada ao problema que será investigado, levando em consideração os objetivos da pesquisa.

\subsubsection{QUANTO A NATUREZA}

Quanto a natureza da pesquisa ela é aplicada, pois a mesma é realizada com base nos dados e conhecimentos para aplicações de soluções para os problemas organizacionais.

\subsubsection{QUANTO AOS FINS}

Quanto aos fins iremos usar a pesquisa explicativa, porque conforme nossos estudos e dados analisados, iremos como a gestão de desempenho organizacional pode influenciar na definição de um plano estruturado de desenvolvimento do capital intelectual, com o objetivo de desenvolver as habilidades dos profissionais e melhorar nos processos organizacionais.

Assim, grande parte das pesquisas explicativas fazem uso do método experimental, no qual permite a manipulação e o controle das variáveis, a fim de identificar a variável independente que gera a causa da variável dependente, ou o fenômeno em estudo (FREITAS, 2014).

\subsubsection{QUANTO AOS MEIOS}

Quantos aos meios, iremos usar a pesquisa bibliográfica utilizando meios e fontes secundárias, como livros, artigos, documentos e sites com o intuito de prover mais interessante e exploratória o problema, com o objetivo de torná-lo mais compreensível sobre a definição de desempenho organizacional nas empresas.

\subsection{CARACTERIZAÇÃO DA EMPRESA}

A empresa FC PARAFUSO foi fundada no dia 27 do mês de maio do ano 2010. A empresa fica localizada na Av. Autaz Mirim, Braga mendes -10069. Sob o CNPJ 18.911.886 0001-90, Cep 69088-245 zona leste de MANAUS, sempre atuando na 
área de vendas para carros novos e seminovos, e atuando também na área de parafuso.

A FC Parafusos comercializa vendas de peças para manutenção e reparação de veículos de linha leve e pesada, e presta serviços para outras empresas, fornecendo soluções completas para mercado de reposição e manutenção de veículos, além de ter uma estrutura para atender até 4 veículos ao mesmo tempo.

A empresa é considerada uma empresa de pequeno porte pois a mesma possui um quadro de 11 funcionários, distribuído nas áreas de vendas, balcão de entrega, caixa e entrega profissionais. Os funcionários possuem grande capacidade de decisão e habilidades concretas para exercer suas atividades com máxima segurança no setor. A FC PARAFUSO tem seu horário de funcionamento de segunda a sábado abrindo sempre as 08:00 da manhã e fechando 18:00 horas.

\section{RESULTADOS E DISCUSSÕES}

Através do diagnóstico organizacional realizado na empresa FC Parafusos, foi confirmado que o setor de recursos humanos é a área mais crítica da organização, sendo está a área responsável pelas estratégias para administrar questões comportamentais internas e também o relacionamento dos colaboradores com a empresa, tornando-se estratégico na administração do capital humano. Conforme o gráfico abaixo.

Gráfico 1- Desempenho por área funcional 


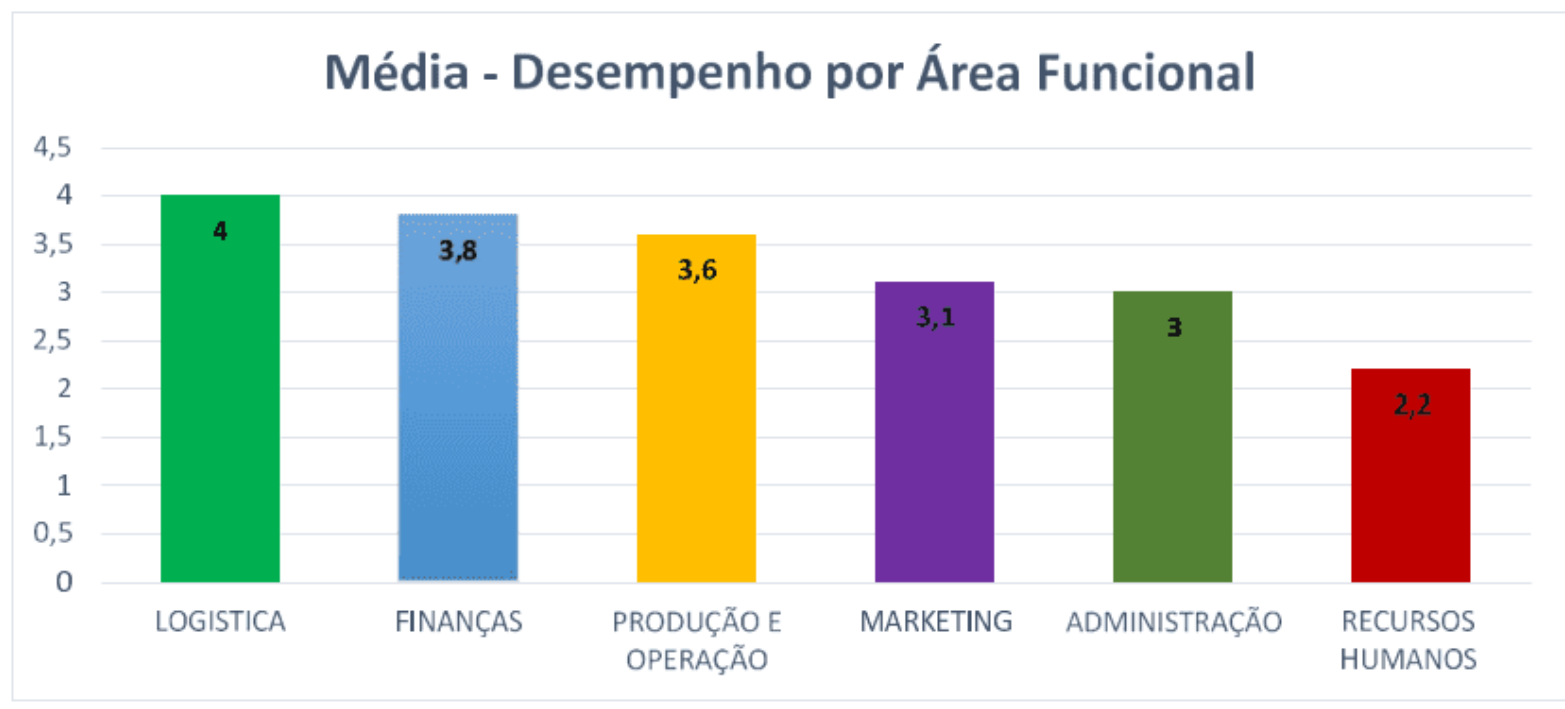

Fonte: Elaborado pelos autores com base na pesquisa documental e entrevista, 2020.

Conforme o Gráfico de desempenho por área funcional percebeu-se que o desempenho da área de recursos humanos foi quem apresentou o indicador mais baixo de $(2,2)$, necessitando de atenção. Com a identificação do ponto crítico o processo permitiu à elaboração da proposta de solução com a finalidade de propor as melhores estratégias de soluções. Pois a empresa em estudo precisa implementar estratégias para que o seu capital intelectual obtenha sucesso para a organização de acordo com o quadro abaixo.

Quadro 1- Quadro da área crítica 


\begin{tabular}{|c|c|c|c|c|c|c|}
\hline & AREA FUNCIONAL & NIVt & EL OU G & RAU DE & AVALIA & ÇÃo \\
\hline & RECURSOS HUMANOS & $\begin{array}{l}\text { Ponto } \\
\text { muito } \\
\text { forte }\end{array}$ & $\begin{array}{l}\text { Ponto } \\
\text { forte }\end{array}$ & $\begin{array}{l}\text { Ponto } \\
\text { médio }\end{array}$ & $\begin{array}{l}\text { Ponto } \\
\text { fraco }\end{array}$ & $\begin{array}{l}\text { Ponto } \\
\text { muito } \\
\text { fraco }\end{array}$ \\
\hline 1 & $\begin{array}{l}\text { Há mão de obra disponivel na empresa proporciona "Capacidade } \\
\text { técnica operativa" }\end{array}$ & & & $x$ & & \\
\hline 2 & $\begin{array}{l}\text { Há empresa presa pela "Formalização das relações trabalhistas } \\
\text { previstas na legislação vigente" }\end{array}$ & $\mathrm{x}$ & & & & \\
\hline 3 & Há rotatividade de pessoal está aceitável (turnover) & & & & $\mathrm{x}$ & \\
\hline 4 & $\begin{array}{l}\text { Há empresa investe em programas de "Motivação dos } \\
\text { trabalhadores" }\end{array}$ & & & & & $\mathrm{x}$ \\
\hline 5 & Há empresa investe "Desenvolvimento técnico profissional" & & & & & $\mathrm{x}$ \\
\hline 6 & $\begin{array}{l}\text { Há empresa estipula "Média de horas de formação por } \\
\text { trabalhador" }\end{array}$ & & & & & $\mathrm{x}$ \\
\hline 7 & $\begin{array}{l}\text { Há empresa possui programa de prevenção " Acidentes no local } \\
\text { de trabalho" }\end{array}$ & & & $\mathrm{x}$ & & \\
\hline 8 & Há possuem programas de recrutamento e seleção estruturado & & & & $\mathrm{x}$ & \\
\hline 9 & As taxas de absenteísmo são aceitáveis & & & & & $\mathrm{x}$ \\
\hline 10 & $\begin{array}{l}\text { Há empresa determina metas individuais de desempenho para } \\
\text { cada colaborador }\end{array}$ & & & $\mathrm{x}$ & & \\
\hline & $\operatorname{AL}(\Sigma)$ & 5 & 0 & 9 & 4 & 4 \\
\hline & DIA POR GRAU (POR COLUNA) & 0,5 & 0 & 0,9 & 0,4 & 0,4 \\
\hline & EMPENHO DA ÁREA ( $\Sigma$ ) TOTAL & & & 2,2 & & \\
\hline
\end{tabular}

Fonte: Elaborado pelos autores com base na pesquisa documental e entrevista, 2020.

Conforme os fatores críticos apresentados no quadro 01 , foram criados os objetivos gerais e específicos com a finalidade de encontrar uma proposta de solução para a melhoria da organização. No entanto, sabemos que para uma organização se manter no mercado é necessário que ela utilize estratégias capazes de prever as necessidades e as imprevisibilidades da causa do problema. Deste modo o problema da pesquisa consiste em: Como a gestão de indicadores de desempenho organizacionais podem influenciar na FC PARAFUSOS de um plano estruturado de desenvolvimento do capital intelectual?

\subsection{PLANEJAMENTO DE AÇÕES}

O planejamento das ações consiste em um planejamento de trabalho necessário para atingir o resultado desejado ou na resolução de um problema. Ou seja, ele pode ser usado para garantir que as atividades possam ser realizadas apontando os 
responsáveis por desenvolver cada uma delas e acompanhar o seu andamento para que se possa atingir os resultados desejados.

Quadro 02 - Ações Intervencivas

\begin{tabular}{|c|c|c|c|c|}
\hline Item & Ação interventiva & Procedente & Cronologia & Custo \\
\hline 01 & $\begin{array}{l}\text { Desenvolver planos } \\
\text { para melhorar na } \\
\text { motivação } \\
\text { funcionários }\end{array}$ & $\begin{array}{l}\text { Recursos } \\
\text { Humanos }\end{array}$ & 2 meses & $\mathrm{R} \$ 1.000,00$ \\
\hline 02 & $\begin{array}{l}\text { Capacitar a equipe para } \\
\text { elaboração de um } \\
\text { planejamento } \\
\text { estratégico continuo e } \\
\text { compartilhado }\end{array}$ & $\begin{array}{l}\text { Recursos } \\
\text { Humanos }\end{array}$ & 2 meses & $R \$ 500,00$ \\
\hline 03 & $\begin{array}{l}\text { Designar as pessoas } \\
\text { certas para os cargos }\end{array}$ & $\begin{array}{l}\text { Recursos } \\
\text { Humanos }\end{array}$ & 2 meses & $\mathrm{R} \$ 800,00$ \\
\hline 04 & $\begin{array}{l}\text { Trabalhar mais no } \\
\text { capital intelectual }\end{array}$ & $\begin{array}{l}\text { Recursos } \\
\text { Humanos }\end{array}$ & 2 meses & $\mathrm{R} \$ 400,00$ \\
\hline \multicolumn{4}{|c|}{ TOTAL } & $\mathrm{R} \$ 2.700,00$ \\
\hline
\end{tabular}

Fonte: Elaborados pelos autores com base pesquisa documental, 2020

As atividades descritas acima se propõem em pôr em prática as propostas apresentadas neste artigo com o intuito de melhorar o desempenho organizacional da empresa estudada em questão, e assim com o auxílio da ferramenta $5 \mathrm{~W} 2 \mathrm{H}$, que é um checklist das atividades que precisam ser desenvolvidas com o máximo de clareza possível por parte dos colaboradores da empresa, foi possível criar um plano de ação para cada problema encontrado.

\subsubsection{DESENVOLVER PLANOS PARA MELHORAR NA MOTIVAÇÃO DOS FUNCIONÁRIOS}


O primeiro passo para execução da proposta de solução é de desenvolver planos para melhorar na motivação dos funcionários, pois nos dias de hoje é preciso que a empresa invista em ações que possam garantir a motivação no trabalho e os funcionários estejam totalmente envolvidos e dedicados para assim se obter um bom desempenho.

Um ambiente com funcionários desmotivados, significa um ambiente em que as pessoas fazem o seu trabalho por obrigação. Há aqueles que acreditam que não se deve dar moleza aos funcionários, porém, devemos lembrar que o trabalho é uma relação de troca, no entanto, se o funcionário não se importa com o trabalho que está desenvolvendo como o mesmo vai se desempenhar 100\% na boa realização.

Deste modo quando os funcionários estão motivados, há uma melhoria no clima organizacional, pois os mesmos trabalham mais engajados, dando seu melhor e trazendo ótimos resultados.

Quadro 03: 5w2h Desenvolver Planos Para Melhorar Na Motivação Dos Funcionários

\begin{tabular}{|l|l|l|}
\hline PERGUNTA & DESCRIÇÃO \\
\hline WHAT & O que fazer? & $\begin{array}{l}\text { Desenvolver planos para melhorar na motivação } \\
\text { dos funcionários }\end{array}$ \\
\hline WHO & Quem fará? & Setor de Recursos Humanos \\
\hline WHERE & Onde será feito? & Em toda Empresa \\
\hline WHEN & Quando fazer? & 2 Meses \\
\hline WHY & $\begin{array}{l}\text { Porque será } \\
\text { feito? }\end{array}$ & $\begin{array}{l}\text { Para uma melhor motivação de todos os } \\
\text { colaboradores }\end{array}$ \\
\hline HOW & Como fazer? & Investir em capacitações, diálogos, palestras... \\
\hline HOW & Quanto custará? & $\mathrm{R} \$ 1.000,00$ \\
MUCH & & \\
\hline
\end{tabular}

Fonte: Elaborado pela equipe, 2020 


\subsubsection{CAPACITAR A EQUIPE PARA ELABORAÇÃO DE UM PLANEJAMENTO ESTRATÉGICO CONTINUO E COMPARTILHADO}

Todo planejamento estratégico visa resultados futuros que dependem do envolvimento de todos. Mais para que esses resultados passar a existir, todos precisam se envolver de verdade e conheçam os investimentos de tempo e recursos na execução desse planejamento.

Além de contar com o engajamento coletivo, é preciso que todo esforço seja continuo e permanente, pois de tempos em tempos o planejamento precisará ser reajustado. Para isso a equipe precisa está motivada e acreditar no pontencial da estratégia. Uma vez que se o colaborador compreende o papel dele no futuro da empresa, ele se sentirá mais motivado a prosseguir com as metas.

Contudo capacitar a equipe é muito importante, já que dessa forma todos terão acesso ao mesmo conhecimento e falarão a mesma língua.

Quadro 04: 5w2h Capacitar A Equipe

\begin{tabular}{|c|c|c|}
\hline \multicolumn{2}{|c|}{ PERGUNTA } & \multirow{2}{*}{$\begin{array}{l}\text { DESCRIÇÃO } \\
\text { Capacitar a equipe para elaboração de um } \\
\text { planejamento estratégico continuo e compartilhado }\end{array}$} \\
\hline WHAT & O que fazer? & \\
\hline WHO & Quem fará? & Setor de Recursos Humanos \\
\hline WHERE & Onde será feito? & Em toda empresa \\
\hline WHEN & Quando fazer? & 2 Meses \\
\hline WHY & $\begin{array}{l}\text { Porque será } \\
\text { feito? }\end{array}$ & $\begin{array}{l}\text { Para uma melhor visão dos resultados futuros da } \\
\text { empresa perante o envolvimento dos funcionários }\end{array}$ \\
\hline HOW & Como fazer? & $\begin{array}{l}\text { Investir em tempo e recursos com o envolvimento } \\
\text { dos funcionários. }\end{array}$ \\
\hline $\begin{array}{l}\text { HOW } \\
\text { MUCH }\end{array}$ & Quanto custará? & $\mathrm{R} \$ 500,00$ \\
\hline
\end{tabular}

Fonte: Elaborado pela equipe, 2020 


\subsubsection{DESIGNAR AS PESSOAS CERTAS PARA OS CARGOS}

Designar as pessoas certas para os cargos é o primeiro e grande passo da empresa. É o processo que vai determinar os requisitos, responsabilidades e esforços impostos por parte da pessoa que vai ocupar um cargo.

Por isso a empresa deve fazer a seleção através de testes, fazendo as perguntas certas e avaliando bem as respostas, deste modo conhecerão melhor as forças e fraquezas dos funcionários. Além de que os funcionários estariam desempenhando melhor suas atividades e trazendo um resultado melhor para a empresa na função ao qual o mesmo se destaca.

Quadro 05: 5w2h - Designar As Pessoas Certas Para Os Cargos

PERGUNTA

DESCRIÇÃO

WHAT O que fazer? Designar as pessoas certas para os cargos

WHO Quem fará? Gerente

WHERE Onde será feito? Setor Administrativo

WHEN Quando fazer? 2 Meses

WHY Porque será feito? Feedback positivo

HOW Como fazer? Seleção através de testes

HOW MUCH Quanto custará? R R 800,00

Fonte: Elaborado pela equipe, 2020.

\subsubsection{TRABALHAR MAIS NO CAPITAL INTELECTUAL}

A busca pelo entendimento do mercado e do negócio é uma constante na rotina dos empresários. Afinal gerir uma empresa é uma tarefa bem complicada e que gera várias 
dúvidas, tal como cuidar bem e investir na equipe constituindo o fator mais importante para o sucesso da empresa.

Por isso o capital intelectual é visto como os pontos positivos da empresa, na vantagem competitiva da mesma. No entanto, a boa gestão desse capital melhora a lucratividade, a posição estratégica, aumenta a fidelidade, reduz os custos operacionais e aumenta a produtividade.

Contudo a FC Parafusos precisa recrutar pessoas que tenham as habilidades certas, que se adequem aos valores e a visão da mesma e que contribuam com o enriquecimento do seu capital intelectual.

Quadro 06: 5W2H Trabalhar mais no capital intelectual

\begin{tabular}{|c|c|c|}
\hline \multicolumn{2}{|c|}{ PERGUNTA } & DESCRIÇÃO \\
\hline WHAT & O que fazer? & Trabalhar mais no capital intelectual \\
\hline WHO & Quem fará? & Assistente administrativo \\
\hline WHERE & Onde será feito? & Setor Administrativo \\
\hline WHEN & Quando fazer? & 2 Meses \\
\hline WHY & $\begin{array}{l}\text { Porque será } \\
\text { feito? }\end{array}$ & Maior vantagem competitiva \\
\hline HOW & Como fazer? & Analisar o que precisa ser melhorado \\
\hline $\begin{array}{l}\text { HOW } \\
\text { MUCH }\end{array}$ & Quanto custará? & $\mathrm{R} \$ 400,00$ \\
\hline
\end{tabular}

Fonte: Elaborado pela equipe 2020.

\subsection{FLUXOGRAMA DA MELHORIA PROPOSTA}

O fluxograma é uma ferramenta usada para representar através de símbolos gráficos, a sequência e a interação das atividades do processo. Estes simbolos são capazes de proporcionar uma visão ampliada do funcionamento do processo, bem como uma descrição mais visual e intuitiva, contribuindo assim para o seu entendimento. 
Cruz (2013, p.115) "entende por fluxograma uma técnica que pode assumir diversas nomenclaturas, formas e pequenos detalhes distintos, mas que não invalidam a ideia geral de desenhar o fluxo de processos".

A FC Parafuso, não possui um fluxograma definido, havendo assim, a necessidade que os autores da pesquisa elaborassem um com base em dados fornecidos. Sabe se que a empresa possui um grande entrave no que se refere se a motivação dos funcionários, e mediante as informações foi declarado que a implementação de recursos para amenizar esse problema é muito baixa. Desse modo optou se em utilizar o fluxograma horizontal, pois o mesmo descreve os processos atuais da FC Parafuso no setor de Recursos Humanos.

Figura 01- Fluxograma Operacional Da Fc Parafuso

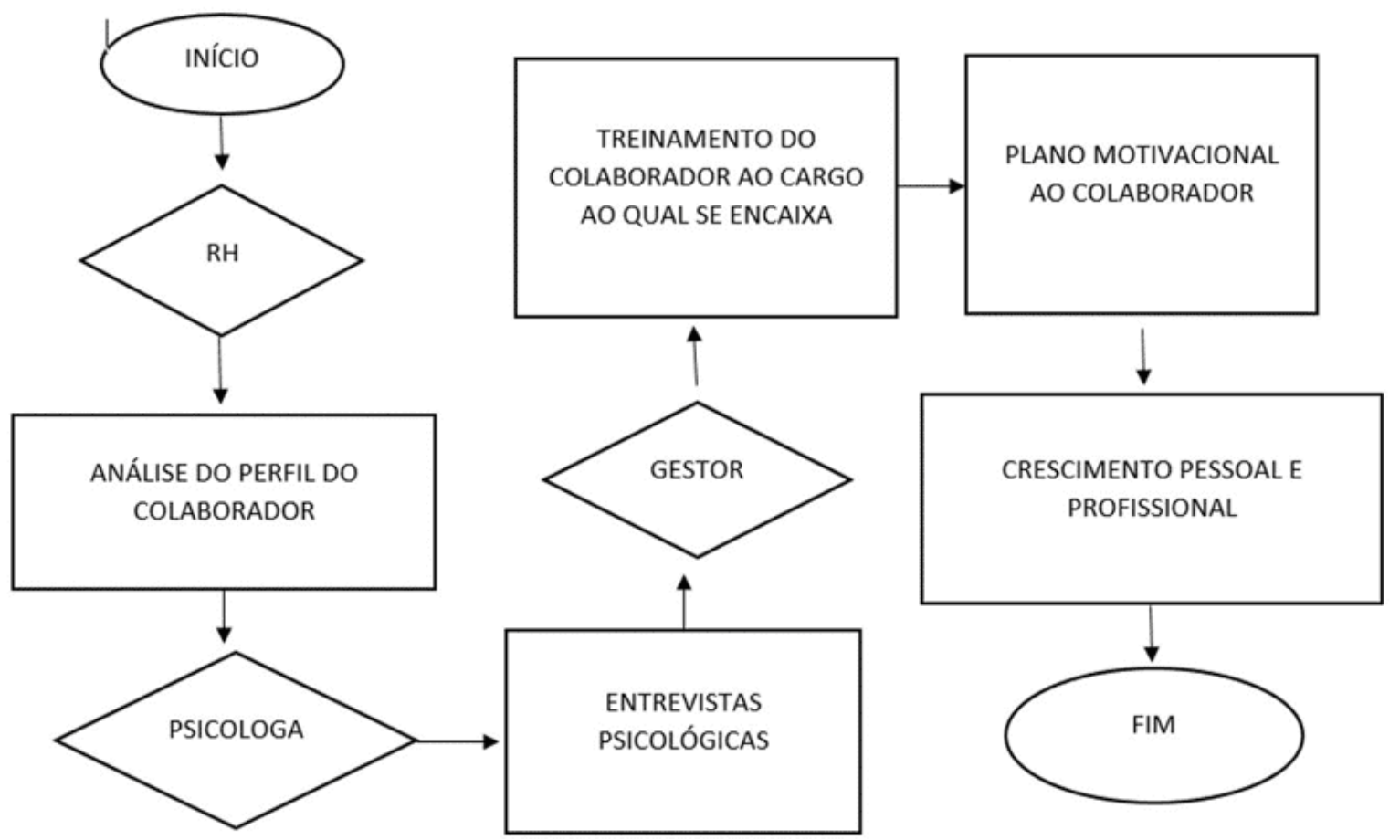

Fonte: Elaborados pelos autores com base na pesquisa documental, 2020.

\section{CONSIDERAÇÕES FINAIS}

O presente artigo teve como finalidade estudar, avaliar e propor melhorias no setor de recursos humanos da empresa FC Parafusos, mais especificamente na área de 
envolvimento do seu capital intelectual, tendo como objetivo propor soluções para implementar estratégias de diferencial competitivo para o capital intelectual da empresa. Em virtude disso, foi desenvolvido um projeto de melhoria com o propósito de melhorar o desempenho organizacional da empresa estudada.

Com as mudanças tecnológicas, houve uma alteração de valores na sociedade, porém a grande questão é saber identificar e divulgar o conhecimento gerado dentro da empresa, promovendo a transformação de seu capital intelectual. Com o diagnóstico realizado na empresa FC Parafusos, pode-se apresentar soluções viáveis e de acordo com a necessidade e realidade em que a empresa se encontra atualmente. Para isso, através do nível de conhecimento teórico e prático, chegou-se as propostas de soluções: desenvolver planos para melhorar na motivação dos funcionários; capacitar a equipe para elaboração de um planejamento estratégico contínuo e compartilhado; designar as pessoas certas para os cargos e trabalhar mais o capital intelectual.

Para a organização do plano de melhoria utilizou-se a ferramenta $5 \mathrm{w} 2 \mathrm{~h}$, tal escolha se deu pelo fato de ser uma ferramenta de fácil entendimento onde qualquer pessoa pode ter uma visão clara do que se pretende chegar. A mesma foi embasada em pesquisas bibliográficas onde foram feitas uma para cada atividade que deve ser desenvolvida no processo de implementação estratégica do capital intelectual.

Conclui-se então que o estudo de caso realizado na empresa FC Parafusos, comprovou que, sob o processo de desenvolvimento de uma empresa com relação aos seus produtos e serviços, a inserção de um capital humano qualificado oriundo do conhecimento adquirido e da experiência das pessoas é essencial, favorecendo assim o alcance dos seus objetivos e o aumento da sua riqueza, bem como, consequentemente demonstrando a importância do capital intelectual para a tomada de decisão no âmbito interno das organizações.

\section{REFERÊNCIAS BIBLIOGRÁFICAS}

CASSOL, A.; GONÇALO, C. R.; SANTOS, A. M.; RUAS, R. L. A Administração 
Estratégica do Capital Intelectual: Um Modelo Baseado na Capacidade Absortiva para Potencializar Inovação. XVII Semead Seminários em Administração, out. 2014.

DERNER, Dália. Gestão estratégica de pessoas. Salvador: UNIFACS, 2013.

EDVINSSON, L. IC 21: Reflections From 21 years of IC practice and theory. Journal of Intellectual Capital, 2013.

JAPIASSÚ, André Miguel. How to prepare and submit abstracts for scientific meetings. Revista brasileira de terapia intensiva, 2013

LIBÓRIO, D.; TERRA, L. Metodologia Cientifica. São Paulo: Rede Internacional de Universidades Laurete, 2015;

MARRAS, Jean Pierre. Avaliação de desempenho humano / Jean Pierre Marras, Marília de Gonzaga Lima e Silva Tose. - Rio de Janeiro: Elsevier, 2012.

MENEZES, Josefa de Fátima. Valorização Humana Como Forma De Retenção De Pessoas Nas Organizações Contemporâneas. Pós-Graduanda em Gestão de Pessoas e Psicologia Organizacional e graduada em Administração de empresas da Faculdade José Augusto Vieira. Revista eletrônica da Faculdade Jose Augusto Vieira. Anovi - №08, setembro 2013- ISSN- 1983-1285.

MOREIRA, Fabiano Greter, et al. Capital intelectual como vantagem competitiva: um estudo bibliográfico. ReCaPe Revista de Carreiras e Pessoas São Paulo. Volume IV - Número 03 - Set/Out/Nov/Dez 2014.

NUNES, André Gomes Ferreira dos Santos. Capital Intelectual e a Vantagem Competitiva. Trabalho Final de Mestrado em Ciências Empresariais. Lisboa, 2013.

RIBEIRO, W. A.; COSTA, D. V. F.; COSTA, M. P. C. BSC: uma estratégia para tomada de decisão e gestão de pessoas. Jornal Eletrônico das Faculdades Integradas, ano V, 1 ed., maio 2014. Disponível em: 
Enviado: Outubro, 2020.

Aproado: Novembro, 2020. 